\title{
Research on the Relationship Between Lifelong Sports Ideological Education and National Fitness Campaign in Higher Vocational Colleges
}

\author{
Deng Huarong \\ School of Art and Design, Heyuan Polytechnic, Guangdong, 517000, China
}

Keywords: Higher vocational colleges, Physical education, National fitness campaign, Sports awareness.

Abstract: Based on the questionnaire survey and rough theoretical analysis of some teachers and students in higher vocational colleges in Guangzhou, this paper holds that physical education in higher vocational colleges is an important part of the national fitness system, and physical education in higher vocational colleges should promote the development of national fitness campaign.

\section{Introduction}

The outline of the National Fitness Program points out that the goal of the National Fitness Program by 2010 is to achieve the coordinated development of sports and national economic and social undertakings, improve the physical and health level of the Chinese nation in an all-round way, and basically build a national fitness system with Chinese characteristics. Physical education in Higher Vocational Colleges undertakes the glorious task of national fitness system and plays an important role in realizing this goal. Higher vocational colleges are places for training professional and technical personnel. The quality of physical education directly affects the effect of physical exercise and students' understanding of physical education. To carry out the national fitness campaign more widely and effectively, the physical education in higher vocational colleges must have a full understanding of the "National Fitness" and strengthen the cultivation of sports awareness and physical education teaching forms to make the effect of physical education more effective and practical. This paper investigates and studies the problems of physical education in Higher Vocational Colleges by means of questionnaires and provides reference for the development and quality improvement of physical education in Higher Vocational colleges to make physical education in Higher Vocational Colleges better adapt to and promote the development of national fitness movement.

\section{Research objects and methods}

In this paper, a questionnaire survey was conducted between March 2001 and September 2002 among teachers and students of Six Higher Vocational Colleges in Guangzhou (see Table 1 for details of the distribution and recovery of the questionnaire). The results of the questionnaire were studied by means of mathematical statistics, systematic analysis and literature review. 
Table 1 Questionnaires and questionnaires for teachers and students

\begin{tabular}{|c|c|c|c|}
\hline $\begin{array}{c}\text { Object of } \\
\text { investigation }\end{array}$ & $\begin{array}{c}\text { Issue a } \\
\text { questionnaire }\end{array}$ & $\begin{array}{c}\text { Recycling } \\
\text { questionnaire }\end{array}$ & Rate of recovery \\
\hline Teacher & 80 & 74 & $92.5 \%$ \\
\hline College student & 420 & 407 & $96.9 \%$ \\
\hline Total & 500 & 481 & $96.2 \%$ \\
\hline
\end{tabular}

\section{PE Teaching in higher vocational colleges should meet the needs of national fitness}

\subsection{Strengthening students' nationwide fitness education}

In the survey of whether the students in Higher Vocational Colleges understand the National Fitness Program, only 1.5\% know it well, 53.4\% know something about it, and $44.6 \%$ do not know it. In the survey of whether to understand the knowledge of "lifelong sports", we found that only $0.8 \%$ knew it well, 35.8\% knew something about it, and 63.3\% did not know it. Through investigation, we can see the fact that at present, physical education in higher vocational colleges is very lack of education and propaganda for national fitness and lifelong sports. In the survey on whether sports have an impact on the current concept of sports and exercise, $27 \%$ of the people think it has a good impact. Such investigation results must arouse our thinking about the development of physical education in higher vocational colleges. The survey results also show that there is a considerable distance between the actual physical education and the modern concept of physical education, physical education in Higher Vocational Colleges and social reality is out of touch. Therefore, to cultivate students' interest and hobbies in physical education, enhance their awareness of physical education, and develop the habit of scientific exercise, we must first carry out systematic and in-depth national fitness education for students.

\subsubsection{Cultivate college students 'interest and hobbies in physical education, enhance their sense of fitness, and help them form the habit of scientific exercise}

By investigating the physical exercise situation of the former graduates of Higher Vocational Colleges, it is found that $83.8 \%$ of the respondents can take part in physical exercise regularly at school, while only $29.7 \%$ of the graduates can take part in physical exercise regularly after they enter the post. However, the number of those who do not take part in physical exercise has risen from $1.4 \%$ to 36. 5\%. As can be seen from Table 3, students in Higher Vocational Colleges believe that school physical education plays a dominant role in students' sports awareness, and we should strengthen students' awareness of lifelong physical education. To cultivate students' lifelong sports consciousness, we must make full use of the time of physical education and extracurricular activities, cultivate students' interest in physical education through theoretical and practical lessons, let students acquire the pleasure of success in mastering every technical action, and form a good sense of self, to enhance their learning motivation and participation confidence.

\subsubsection{Strengthening health education for students.}

The students in Higher Vocational Colleges believe that physical exercise is still the most important factor to promote health, followed by healthy psychology, eating habits, living habits, bad habits and other health care problems. Nutrition in modern society is no longer a major factor affecting health. To strengthen students' health education, we must adopt comprehensive and effective educational means and measures so that students can understand the connotation and extension of health, know how to effectively strengthen their physique, let them understand the 
basic laws and requirements of promoting health, and master the basis of nutritional health care, health care, sports health care, psychological health care and social health care. This knowledge and basic skills, to effectively and consciously eliminate and avoid all kinds of factors affecting or endangering health, more to engage in health care requirements to achieve the purpose of enhancing physical fitness and health.

\subsection{Strengthening the construction of Physical Education Curriculum}

Physical education curriculum is the main form and way to achieve the goal of physical education in higher vocational colleges. Facing the requirements of society, science, technology and economic development for talents in the 21st century, the curriculum construction of higher vocational colleges should incorporate the cultivation of students' physical and mental health, mental health, moral health and social adaptability into the goal of promoting students' all-round development of body and mind. On the one hand, we should attach importance to the value of physical education so that it can promote the comprehensive development of students' body and mind, break through the old system of sports technology teaching, establish the basic goal of promoting students' normal physical and mental development, strengthening their physique and improving their health, attach importance to the teaching of sports culture and health care knowledge, and form a combination of physical exercise. A new system combining sports and health care education. On the other hand, we should pay attention to the elasticity and specialization of the teaching content, so that the teaching content is not only unified, but also diversified, flexible and personalized. Higher Vocational Colleges should, according to their own actual situation, add new teaching materials, increase the choice of teaching materials, and ensure the continuity and completeness of teaching content based on avoiding repetition of teaching contents in universities, middle schools and primary schools.

\subsubsection{The formulation of the outline}

The syllabus is the guiding document of physical education teaching and the basis of compiling teaching materials and teaching management. Students in higher vocational colleges only pay attention to the study of physical exercise methods, principles, sports techniques and sports health care knowledge, but ignore the study of lifelong sports knowledge and national fitness program. Therefore, in formulating the syllabus, according to the characteristics of higher knowledge level, stronger understanding and thinking ability of College students, we should increase the depth of such topics as "methods and principles of physical exercise", "knowledge of physical health care", "knowledge of lifelong physical education" and "national fitness program" to expand and deepen the principles of physical exercise. Principles, methods and sports health care knowledge, for the cultivation of students' ability to exercise independently lay a good theoretical foundation.

\subsubsection{Setup of practical courses}

After students enter the job, their fitness programs tend to develop in the direction of fitness and entertainment, and they gradually lose interest in competitive, stimulating and intensive sports. The survey results also show that, due to the limitations of venues, equipment and other conditions, the current physical training projects in Higher Vocational colleges, mainly concentrated in venues, equipment requirements are not high on the project. The result shows that the physical education teaching in higher vocational colleges should not only enable students to master the basic knowledge, skills and scientific methods of physical exercise, but also strengthen the popularization of national fitness, the improvement of sports facilities and the enhancement of sports consciousness. 


\subsubsection{Take fitness as the goal, and make competitive sports teaching material}

Competitive sports are the main material of physical education curriculum. In many cases, it can promote the formation and development of students' basic activity ability, sports ability, self-exercise ability and so on. However, the content of physical education in higher vocational colleges should aim at fitness, strengthen the close relationship between teaching materials and society and life, and lead competitive sports to entertainment sports, leisure sports, health care sports, interesting sports and so on. Although physical education is no longer mainly to teach competitive sports, but still can be regarded to achieve sports goals, but no longer to improve the level of sports technology or pursuit of sports performance as the main purpose.

\subsubsection{Increase students' time for physical education and physical exercise}

In formulating the new syllabus, we should increase the time of PE class and extracurricular activities, and especially increase the proportion of PE theory class in PE class. In the survey of PE class time for college students in Higher Vocational colleges, 4.1\% thought it was half a year, 24.3\% thought it was one year, and $70.3 \%$ thought it was two years. It is not difficult to see that the students in Higher Vocational Colleges attach importance to physical education in college and the value of physical education to their own fitness. Physical education is the main place for students to learn sports knowledge, technology, skills and cultivate sports awareness. Accordingly, increasing the teaching time of physical education in higher vocational colleges will greatly promote the further development of physical education in Higher Vocational colleges.

\subsubsection{Physical education should change its focus.}

Physical education should change its focus from "teacher-centred" to "environment-oriented" to meet the needs of national fitness. Strengthen the improvement of teaching methods, so that students can not only learn sports skills as soon as possible, but also master the methods of physical exercise. Physical education in higher vocational colleges should first meet the individual needs of students. Teachers should adhere to the principle of teaching students in accordance with their aptitude and treating them differently to solve the problems of "not enough to eat" and "not enough to eat". At the same time, they must increase the time for students to study independently to create a good learning atmosphere for students, including good teaching methods and correct teaching methods. Technical guidance, good venues, equipment, mutual understanding between students, teachers and students, mutual support and mutual trust. $8.1 \%$ of the students in higher vocational colleges thought that teachers should be strict with classroom teaching organization and students should abide by classroom discipline, $89.2 \%$ thought that teachers should give students greater freedom of movement, strict and not tight, living without disorder; $2.7 \%$ thought that students could live freely according to their own interests. Move. From the above investigation, college students' evaluation of physical education is in line with the direction of physical education in Higher Vocational colleges.

\section{Conclusion}

From the results of the investigation and the data, we can see that the physical education teaching in higher vocational colleges has not achieved satisfactory results in the national fitness program. Therefore, the main task of physical education in higher vocational colleges is to enhance students' awareness of lifelong physical education. "Lifelong Physical Education" should become the guiding ideology of physical education in Higher Vocational colleges, which is also the necessary theoretical basis to integrate with the national fitness. Higher vocational colleges should publish the 
"School Physical Education Reform and Development Plan" with the guiding ideology of lifelong physical education as soon as possible to guide and standardize the development and improvement of physical education in Higher Vocational Colleges at present and in the future.

\section{Acknowledgements}

The paper is supported by the Research on the development strategy of the national fitness campaign.

\section{References}

[1] Wu Jingyi. Innovation and Practice of Physical Education Teaching Model in Higher Vocational Colleges [A]. Scientific Research Achievements of Research on Teacher's Teaching Ability Development (Volume 12) [C]: General Research Group of Teacher's Teaching Ability Development, 2017:5.

[2] Huang Xiaoqiang.Research on the present situation and reform and development of social sports major in higher vocational sports colleges[J].Contemporary sports science and technology, 2016,6(04): 126-127.

[3] Li Xiaoyan. Socialized management of sports venues in Higher Vocational Colleges in China, [J]. movement, 2014 (09): 137-138.

[4] Gong Bo. Investigation and Research on the current situation of football development in Higher Vocational Colleges in Wuxi [D]. Soochow University, 2013.

[5] Wang Xiao.Thoughts on the Cultivation of "Learning-Innovation-Service" PE Teachers in Higher Vocational Colleges[J].Journal of Sports Adult Education, 2011,27(02): 89-90. 